\title{
Development and Validation of UV-Spectrophotometric Method for Estimation of Metformin Hydrochloride and Pioglitazone in Tablet Dosage Form
}

\author{
Mrs. Rupali S. Joshi, Mr. Ajit K. Nangare, Miss. Deepali S. Sanap and Miss. Surekha M. Sase \\ Dr. Vithalrao Vikhe Patil Foundation's College of Pharmacy, Vilad Ghat, Ahmednagar, 414 111, India
}

\begin{abstract}
Simple, sensitive, rapid and accurate UV spectroscopic methods have been developed for the estimation of metformin hydrochloride and pioglitazone in tablet dosage forms. Simultaneous estimation and dual-wavelength methods were developed and validated using solvent methanol. Both drugs show linearity at $5-40 \mu \mathrm{g} / \mathrm{ml}$ for both methods. The suggested techniques have been effectively implemented in pharmaceutical formulations to the evaluation of quoted drugs. Recovery research was conducted to verify the method's accuracy, precision. The techniques have been validated under ICH guidelines.
\end{abstract}

Keywords: Metformin hydrochloride, Pioglitazone, Simultaneous estimation method and Dual wavelength method.

Article Info: Received 10 July 2019; Review Completed 18 Aug 2019; Accepted 23 Aug 2019; Available online 30 Aug 2019

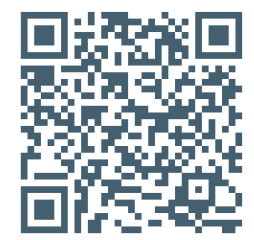

Cite this article as:

Joshi RS, Nangare AK, Sanap DS, Sase SM, Development and Validation of UV-Spectrophotometric Method for Estimation of Metformin Hydrochloride and Pioglitazone in Tablet Dosage Form, Journal of Drug Delivery and Therapeutics. 2019; 9(4-A):381-384 http://dx.doi.org/10.22270/jddt.v9i4-A.3499

Mrs. Rupali S. Joshi, Dr. Vithalrao Vikhe Patil Foundation's College of Pharmacy, Vilad Ghat, Ahmednagar, 414 111, India

\section{INTRODUCTION:}

Piomar 7.5-MF tablets contain two oral anti-hyperglycemic drugs that contain metformin hydrochloride and Pioglitazone. Metformin Hydrochloride is a biguanide class of antidiabetic drug. Chemically, metformin hydrochloride is a $\quad(\mathrm{N}, \quad \mathrm{N}$-dimethyl Imidodicarbonimidic diamide monohydrochloride) as shown in Figure 1.<smiles>CN(C)C(=N)NC(N)N</smiles>

Figure 1. Metformin hydrochloride

Metformin hydrochloride used to treat diabetes mellitus-II. It decreases the glucose absorption in the small intestine, increases glucose transport into cells, decreases the plasma frees fatty acid concentrations and inhibits gluconeogenesis. Activation of AMPK plays a vital role in these processes. It improves hepatic and peripheral issue sensitivity to insulin without the problem of series lactic acidosis. Metformin hydrochloride is official in BP, Martindale and Merck Index.
Pioglitazone is an oral antihyperglycemic agent that mainly operates by reducing resistance to insulin. Chemically specified as ( \pm )-5-[[4-[2-(5-ethyl-2-pyridinyl)ethoxy] methyl]-2, 4-thiazolidinedione as shown in figure 2 . Molecular formula and molecular weight are C19H20N2O3S and $356.44 \mathrm{~g} / \mathrm{mol}$ respectively. It is not official in any pharmacopeia. It has been used together in combination to achieve better glycolic control and patient compliance. This paper aimed to explore the possibility of using techniques of simultaneous estimation method and dual-wavelength methods for quantifying metformin hydrochloride and pioglitazone simultaneously in their mixture form. The advantage of these proposed methods is that no separation is required. The proposed procedures are simple, rapid and act as a convenient alternative to the HPLC method.<smiles>CCc1ccc(CCOc2ccc(CC3SC(=O)NC3=O)cc2)nc1</smiles>

Figure 2. Pioglitazone 
Literature survey revealed that reports on analytical methods such as UV-Visible, HPLC, LC-MS, LC-MS/MS and HPTLC for the determination of metformin hydrochloride and pioglitazone from the bulk and dosage form, very few analytical methods reported for metformin hydrochloride and pioglitazone. The present investigation was carried out in the view of establishing a simple, rapid, accurate, economical, precise and robust UV method for estimation metformin hydrochloride and pioglitazone in bulk and tablet dosage form using methanol as the solvent.

\section{METHOD DEVELOPMENT:}

\section{PREPARATION OF STANDARD STOCK SOLUTION:}

Standard metformin hydrochloride stock solution $(100 \mu \mathrm{g} / \mathrm{ml})$ :

Accurately weighed metformin hydrochloride $(10 \mathrm{mg})$ was transferred to a $100 \mathrm{ml}$ volumetric flask. Dissolved it in methanol and make up the volume with the same. Dilutions from stock solution were prepared in the range of 5-40 $\mu \mathrm{g} / \mathrm{ml}$.

\section{Standard pioglitazone stock solution $(100 \mu \mathrm{g} / \mathrm{ml})$ :}

Accurately weighed pioglitazone $(10 \mathrm{mg})$ was transferred to a $100 \mathrm{ml}$ volumetric flask and dissolved in methanol to the mark with methanol. Dilutions from stock solution were prepared in the range of $5-40 \mu \mathrm{g} / \mathrm{ml}$.

Methanol was used as a blank solution.

\section{METHOD A: SIMULTANEOUS DETERMINATION}

The standard solutions of metformin hydrochloride and pioglitazone were scanned separately in the range of 200 to $400 \mathrm{~nm}$ against methanol as blank and wavelengths of maximum absorbance were determined. The concentrations of drugs were determined using the following equations:

$C x=\frac{\left(A_{2} \times a_{1}-A_{1} \times a_{2}\right)}{\left(a_{2} \times a_{1}-a_{1} \times a_{2}\right)}-------$ Equation no. 1
$C y=\frac{\left(A_{1} \times a_{2}-A_{2} \times a_{1}\right)}{\left(a_{2} \times a_{1}-a_{1} \times a_{2}\right)}-$------- Equation no. 2

Where,

$\mathrm{Cx}=$ Concentration of metformin hydrochloride in gm/lit $\mathrm{Cy}=$ Concentration of pioglitazone in gm/lit

$\mathrm{A}_{2}=$ Absorbance of sample solution at $225.4 \mathrm{~nm}$

$\mathrm{A}_{1}=$ Absorbance of sample solution at $237.4 \mathrm{~nm}$

ax $1=$ absorptivity of metformin hydrochloride at $237.4 \mathrm{~nm}$

ay $_{1}=$ absorptivity of pioglitazone at $237.4 \mathrm{~nm}$

$\mathrm{ax}_{2}=$ absorptivity of metformin hydrochloride at $225.4 \mathrm{~nm}$

$\mathrm{ay}_{2}=$ absorptivity of pioglitazone at $225.4 \mathrm{~nm}$

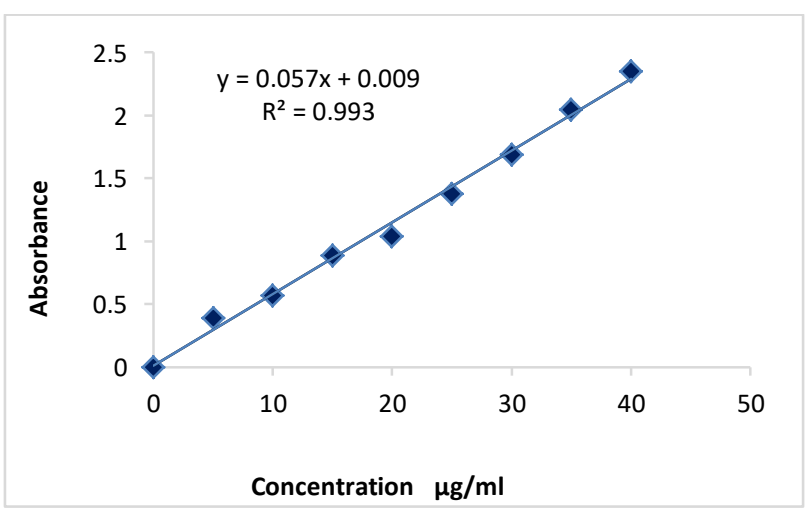

Figure 3. Calibration Curve of Metformin Hydrochloride



Figure 4. Calibration Curve for Pioglitazone

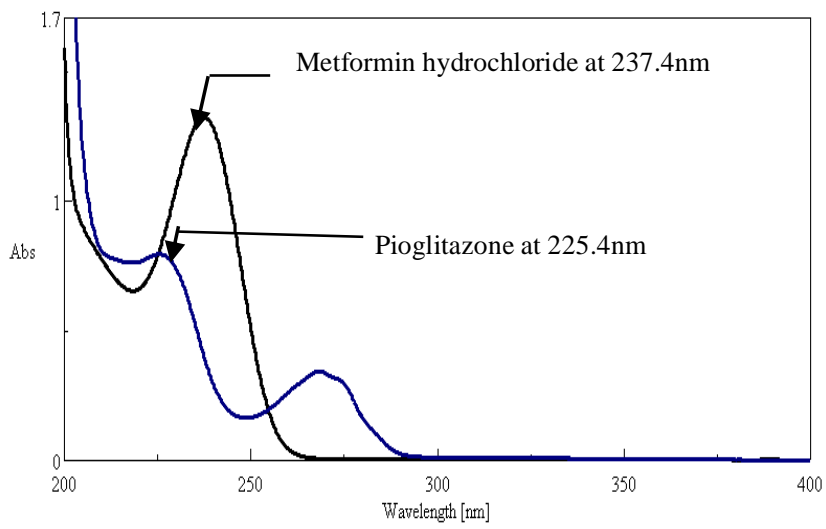

Figure 5. Overlain Spectra of Metformin Hydrochloride and Pioglitazone

\section{METHOD B: DUAL WAVELENGTH METHOD}

In this method, two wavelengths were selected for each drug in a way so that the difference in absorption is zero for one drug at a time. As per the spectrum, we found that the absorption of metformin hydrochloride was the same at $232.4 \mathrm{~nm}$ and $241.8 \mathrm{~nm}$ so that these wavelengths were selected for the estimation of pioglitazone and same as in $264.8 \mathrm{~nm}$ and $272.8 \mathrm{~nm}$ absorption of pioglitazone were same hence these two wavelengths were selected for estimation of metformin hydrochloride. At these selected wavelengths, all the mixed standard was scanned and a calibration curve between the absorbance difference and the respective concentrations was plotted. The value of the coefficient of correlation was 0.993 and 0.996 for metformin hydrochloride and pioglitazone respectively. The sample solutions were evaluated at chosen wavelengths and to obtain the concentration values of variation in absorption were extrapolated to the working standard curve.

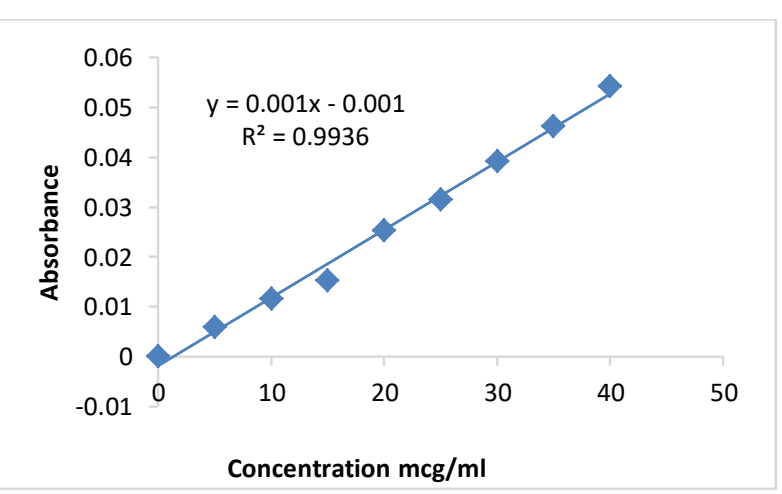

Figure 8 Calibration Curve for Metformin Hydrochloride 


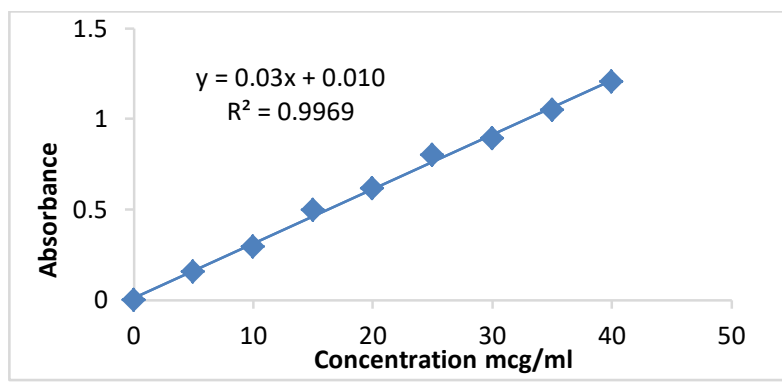

Figure 9 Calibration Curve for Pioglitazone

\section{ANALYSIS OF TABLET DOSAGE FORMS ANALYSIS OF TABLET FORMULATIONS}

For the estimation of drugs from the tablet dosage form, twenty tablets of metformin hydrochloride and pioglitazone in combination were weighed accurately and the average weight per tablet was calculated. Tablets were ground to a fine powder a quantity equivalent to $10 \mathrm{mg}$ of metformin hydrochloride and $0.15 \mathrm{mg}$ of pioglitazone was transferred to a volumetric flask and was extracted with $100 \mathrm{ml}$ of methanol. The extract was filtered using Whatman filter paper, and the filtrate was approximately diluted to get a final concentration for both metformin hydrochloride and pioglitazone. The solution was further diluted to get a final concentration of $20 \mu \mathrm{g} / \mathrm{ml}$ of the formulation. The absorbance of the solution was measured at their maximum wavelength.

The values of the absorptions were substituted in the respective formulas (Equation no.1 \& 2) to obtain the content of metformin hydrochloride and pioglitazone. In the dual-wavelength method, the sample solution was scanned at $232.4 \mathrm{~nm}$ and $241.8 \mathrm{~nm}$ for pioglitazone while $264.8 \mathrm{~nm}$ and $272.8 \mathrm{~nm}$ for metformin hydrochloride. The concentration of metformin hydrochloride and pioglitazone was determined from their calibration curve plotted between absorption difference and concentration. The results of the analysis are given in Table 1.

\section{VALIDATION:}

The method was developed and validated according to the analytical procedure as per the ICH guidelines for validation of analytical procedures to determine linearity, accuracy, precision, ruggedness, and robustness for the analytes i.e. metformin hydrochloride and pioglitazone.

\section{Linearity:}

An analytical method's linearity is its ability to produce test results that are proportional to the concentration of the analytes within a given range in samples. The linearity of measurement was evaluated by analyzing different concentration of the standard solution of metformin hydrochloride and pioglitazone. Calibration curves were built and the suggested technique was assessed in the respective statistical study by its correlation coefficient and intercept value calculated. For both the method, the BeerLambert's concentration range was found to be $5-40 \mu \mathrm{g} / \mathrm{ml}$.

\section{Precision:}

An analytical procedure's accuracy reflects the proximity of agreement (degree of scattering) between sequences of measurements acquired under the prescribed circumstances from the various sampling of the same homogeneous sample.

Precision can be taken into account at three levels: repeatability, intermediate (intraday) precision and reproducibility (interday precision).

1] Intraday Precision:

Solutions containing 10, 15, $20 \mu \mathrm{g} / \mathrm{ml}$ of Metformin $\mathrm{HCl}$ and $10,15,20 \mu \mathrm{g} / \mathrm{ml}$ of Pioglitazone were analyzed three times on the same day and \%R.S.D was calculated.

\section{2] Interday Precision:}

Solutions containing 10, 15, $20 \mu \mathrm{g} / \mathrm{ml}$ of Metformin $\mathrm{HCl}$ and $10,15,20 \mu \mathrm{g} / \mathrm{ml}$ of Pioglitazone were analyzed on three different successive days and \%R.S.D was calculated.

\section{3] Repeatability:}

Method precision of the experiment was performed by preparing the standard solution of Metformin $\mathrm{HCl}(15$ $\mu \mathrm{g} / \mathrm{ml})$ and Pioglitazone $(15 \mu \mathrm{g} / \mathrm{ml})$ for six times and analyzed as per the proposed method.

\section{Limit of Detection (LOD):}

The detection limit can be calculated using the following equation in accordance with ICH rules.

$\mathrm{LOD}=3.3 \times(\mathrm{N} / \mathrm{S})$

Where, $\mathrm{N}=$ Standard deviation of the drug's peak areas $\mathrm{S}=$ Slope of the respective calibration curve.

\section{Limit of Quantification (LOQ):}

The quantification limit can be calculated using the following equation in accordance with ICH rules.

$\mathrm{LOQ}=10 \times(\mathrm{N} / \mathrm{S})$

Where, $\mathrm{N}=$ Standard deviation of the drug's peak areas $\mathrm{S}=$ Slope of the respective calibration curve.

Table no.1 Optical Characteristics and Validation Study of Formulation

\begin{tabular}{|c|c|c|c|c|}
\hline \multirow{2}{*}{ Parameters } & \multicolumn{2}{|c|}{ Method A } & \multicolumn{2}{c|}{ Method B } \\
\cline { 2 - 5 } & Metformin HCl & Pioglitazone & Metformin HCl & Pioglitazone \\
\hline Wavelength $\lambda$ max $(\mathrm{nm})$ & 237.4 & 225.4 & 264.8 and 272.8 & 232.4 and 272.8 \\
\hline Beer's law limit $(\mu \mathrm{g} / \mathrm{ml})$ & $5-40$ & $5-40$ & $5-40$ & $5-40$ \\
\hline Correlation coefficient $\left(\mathrm{R}^{2}\right)$ & 0.993 & 0.994 & 0.9936 & 0.9969 \\
\hline Slope & 0.057 & 0.041 & 0.001 & 0.03 \\
\hline Intercept & 0.009 & 0.029 & 0.0019 & 0.01 \\
\hline SD & 0.698 & 0.507 & 0.0172 & 0.365 \\
\hline RSD & 54.06 & 54.03 & 60.33 & 53.15 \\
\hline Precision & & & & 0.49 \\
Interday (\% RSD) & 0.081 & 0.156 & 0.54 & 0.22 \\
\hline Intraday (\% RSD) & 0.167 & 0.20 & 56.76 & 40.15 \\
\hline LOD $(\mu \mathrm{g} / \mathrm{ml})$ & 40.41 & 40.80 & 172 & 121.66 \\
\hline LOQ $(\mu \mathrm{gg} / \mathrm{ml})$ & 122.45 & 123.65 & & \\
\hline
\end{tabular}


Table No. 2 Tablet Analysis Data for Both Methods

\begin{tabular}{|c|l|c|c|c|}
\hline Method & \multicolumn{1}{|c|}{ Drugs } & Label claim & Amount recovered & \% Recovery \\
\hline A & Metformin hydrochloride & 500 & 501 & 100.2 \\
& Pioglitazone & 7.5 & 7.45 & 99.33 \\
\hline b & Metformin hydrochloride & 500 & 497.5 & 99.5 \\
& Pioglitazone & 7.5 & 7.4 & 98.66 \\
\hline
\end{tabular}

\section{RESULT AND DISCUSSION:}

Simple, precise and accurate simultaneous equation and dual-wavelength methods were developed for the simultaneous estimation of metformin hydrochloride and pioglitazone in combined dosage forms. The wavelengths used for the simultaneous equation were $225.4 \mathrm{~nm}$ and $237.4 \mathrm{~nm}$; and for dual-wavelength method, it was $232.4 \mathrm{~nm}$, $241.8 \mathrm{~nm}, 264.8 \mathrm{~nm}$ and $272.8 \mathrm{~nm}$. Beer's law obeyed in a concentration range of $5-40 \mu \mathrm{g} / \mathrm{mL}$ for both metformin hydrochloride and pioglitazone for both the methods. The absorptivity and absorbance were determined and the values were substituted in the equation to obtain the results. Two commercial formulations containing metformin hydrochloride and pioglitazone were analyzed by the proposed method. The percentage relative standard deviation for precision and accuracy was found to be low, which indicates that the method has considerable accuracy and precision.

Standard calibration curves of metformin hydrochloride and pioglitazone for method II were linear with correlation coefficient (R2), slope and intercept 0.993, 0.001 and $0.001 ; 0.996,0.03$ and 0.01 respectively. Recovery greater than $98.6 \%$ with the low standard deviation justifies the accuracy of the method. The results are in good agreement with the label claim. The suggested technique is discovered to be easy, precise, accurate and delicate and can, therefore, be used as a quality control instrument to simultaneously estimate both drugs in the quality control laboratory from their mixed dosage form.

\section{REFERENCES:}

1. Joshi RS, Pund R, Kadam A, Quantitative estimation and validation of ofloxacin and ornidazole in tablet dosage form by hydrotropic solubilization phenomenon, Der pharma lettre, 2016;8(6):269-274.

2. Joshi RS, Bhandari P, Sangle D, Application of hydrophobic solubilization technique for simultaneous estimation and validation of ofloxacin and ornidazole in tablet dosage form, Der pharma lettre, 2015;7(11):234-240.

3. Tarkase KN, Suryawanshi SS, Joshi RS, Simultaneous derivative spectrophotometric determination and validation of losartan potassium in pharmaceutical dosage form, International journal of pharmaceutical sciences review and research, 2012;13(2):31-

4. Dange YD, Honmane SM, Bhinge SD, Salunkhe VR, Jadge DR, Development and validation of UV-spectrophotometric method for estimation of metformin in bulk and tablet dosage form, Indian journal of pharmaceutical education and research, 2017;51(4S):S754-S760.

5. Karim R, Poly N, Banoo R, Development and validation of UV spectroscopic method for the determination of metformin hydrochloride in tablet dosage form, International journal of pharmaceutical sciences and research, 2012;3(9):3170-3174.

6. Singh VV, Chaudhary P, Hema B, Tiwari R, Method development of Pioglitazone by UV Spectrophotometer, International journal of drug development and research, 2014,6(4):80-83.

7. Chungath TT, Reddy YP, Devanna N, Simultaneous spectrophotometric estimation of metformin hydrochloride and glipizide in tablet dosage forms, International journal of pharmtech research, 2011;3(4):2064-2067.

8. Dhabale PN, Seervi CR, Simultaneous UV spectrophotometric method for estimation of gliclazide and metformin hydrochloride in tablet dosage form, International journal of chemtech research, 2010;2(2): 813-817.

9. Mali AD, Mali $S$, Tamboli A, Bathe $\mathrm{R}$, Simultaneous UV spectrophotometric methods for estimation of metformin $\mathrm{HCl}$ and glimepiride in bulk and tablet dosage form, International journal of advances in pharmaceutics, 2015;4(6):117-124.

10. Goswami L, Mukhopadhyay S, Durgapal S, Simultaneous estimation of metformin and pioglitazone by ultraviolet spectrophotometry, Indian journal of pharmaceutical sciences, 2010; 72 (4):508-510.

11. Mubeen G, Noor K, Spectrophotometric method for analysis of metformin hydrochloride, Indian journal of pharmaceutical sciences, 2009; 71(1):100-102.

12. Arayne MS, Sultana N, Zuberi MH, Siddiqui FA, Spectrophotometric quantitation of metformin in bulk drug and pharmaceutical formulations using multivariate technique, Indian journal of pharmaceutical sciences, 2009;71(3):331-335. 